This article was published in Water Research, 54, 327-336, 2014

http://dx.doi.org/10.1016/j.watres.2014.02.003

\title{
Insights into the relationship between antimicrobial residues and bacterial populations in a hospital-urban wastewater treatment plant system
}

Ana Rita Varela ${ }^{a, c}$, Sandra Andre ${ }^{b}$, Olga C. Nunes ${ }^{c}$, Ce'lia M. Manaia ${ }^{a, *}$

a $C B Q F$ e Centro de Biotecnologia e Química Fina, Laboratório Associado, Escola Superior de Biotecnologia, Universidade Católica Portuguesa/Porto, Rua Dr. António Bernardino Almeida, 4200-072 Porto, Portugal

b Agência Portuguesa do Ambiente, I.P., 2610-124 Amadora, Portugal

C LEPABE e Laboratory for Process Engineering, Environment, Biotechnology and Energy, Faculty of Engineering, University of Porto, Rua Dr. Roberto Frias, 4200-465 Porto, Portugal

\section{Abstract}

The relationship between antimicrobial residues, antibiotic resistance prevalence and bacterial community composition in hospital effluent and in the receiving wastewater treatment plant was studied. Samples from hospital effluent, raw inflow and final effluent of the receiving wastewater treatment plant were characterized for amoxicillin and ciprofloxacin resistance prevalence, content of heavy metals and antimicrobial residues and bacterial community structure, based on $16 \mathrm{~S}$ rRNA gene PCR-DGGE analysis. The concentration of fluoroquinolones, arsenic and mercury was in general higher in hospital effluent than in raw inflow, while the opposite was observed for tetracyclines, sulfonamides and penicillin G. The prevalence of ciprofloxacin resistance was significantly higher in hospital effluent than in raw inflow. The concentration of antimicrobial residues was observed to be significantly correlated with the prevalence of antibiotic resistant bacteria and with variations in the bacterial community. Hospital effluent was confirmed as a relevant, although not unique, source of antimicrobial residues and antibiotic resistant bacteria to the wastewater treatment plant. Moreover, given the high loads of antibiotic residues and antibiotic resistant bacteria that may occur in hospital effluents, these wastewater habitats may represent useful models to study and predict the impact of antibiotic residues on bacterial communities. 


\section{Introduction}

Over the last decades, bacterial resistance to antibiotics has become an issue of growing concern worldwide (French, 2010), frequently attributed to the excessive use of antibiotics (Kim and Aga, 2007; Martinez, 2009). Antimicrobial residues can impose selective pressures, capable of favoring the proliferation of resistant bacteria, with the progressive elimination of the susceptible organisms. Simultaneously, antimicrobial residues may induce bacteria to transfer horizontally antibiotic resistance genes for other community members (Davies and Davies, 2010; Gillings, 2013). It is estimated that antibiotic concentrations measured in environmental samples, such as rivers, can inhibit wild-type bacteria (Tello et al., 2012). Due to such inhibition, antimicrobial residues would be also implicated in the rearrangement of the bacterial communities. This hypothesis was recently supported by the demonstration of significant correlations between the concentrations of antimicrobial residues, antibiotic resistant bacteria or their genes and rearrangements of the bacterial communities in surface and wastewater (Huerta et al., 2013; Novo et al., 2013). In spite of these evidences that could lead to an apparently simple cause-effect relationship, the complexity of propagation of antibiotic resistance in the environment is widely recognized. Intriguing questions are, for example, the effect of sub-inhibitory concentrations of antibiotics on the bacterial communities or on the stability of the resistance phenotypes, even in the absence of selective pressures (Andersson and Hughes, 2010, 2012). The association between the classes of antimicrobial residues found in a given environment and the major types of antibiotic resistance occurring in the same site are also not well understood (Oberlé et al., 2012; Huerta et al., 2013; Novo et al., 2013).

Health care facilities, where the use of antibiotics is more frequent and intensive and where antibiotic resistant bacteria may have a selective advantage over the susceptible counterparts, are regarded as important reservoirs of antibiotic resistance (Kü mmerer and Henninger, 2003; Jakobsen et al., 2008; Galvin et al., 2010; Harris et al., 2013; Varela and Manaia, 2013). In addition, in urban areas, wastewater treatment plants represent important receptors for antimicrobial residues and antibiotic resistant bacteria (Manaia et al., 2012; Michael et al., 2013; Rizzo et al., 2013). This situation may be worsened when untreated effluents from health care facilities are received in the urban wastewater treatment plants. Nevertheless, there are no legal requirements for hospital effluents treatment prior to its discharge in the municipal collector. In spite of the potential risks of hospital effluents regarding their role as possible suppliers of antibiotic resistant bacteria to the environment, these effluents 
represent useful models to assess both the relationship between antibiotic residues and antibiotic resistance and the influence that they may display in the receiving wastewater treatment plant.

The potential effects on microbiome due to pollution with antibiotics have received little attention. However, additional knowledge in this area is fundamental to assess the risks associated with the environmental spread of resistance genes and to control potential adverse effects for human well-being (Gillings, 2013). The current study was based on the hypothesis that hospital effluent is an important supplier of antimicrobial residues and of antibiotic resistant bacteria to the receiving wastewater treatment plant, yielding higher levels of both types of contaminants. Moreover, it was hypothesized that given the different levels of antimicrobial residues and antibiotic resistance observed in hospital and municipal effluents, these wastewater systems would provide interesting insights into the relationship between antimicrobial residues, antibiotic resistant populations and bacterial communities. The assessment of those hypotheses also aimed to infer about the impacts that hospital effluents may have on the occurrence of antimicrobial residues and of antibiotic resistant bacteria in the respective municipal wastewater treatment plant.

\section{Materials and methods}

This study examined samples from a hospital effluent, and from the raw and treated wastewater of the respective urban treatment plant, located in the northern region of Portugal (Varela and Manaia, 2013). The hospital included in this study serves a population of 3 million people, covering more than 30 clinical specialties and having a capacity of 1120 beds. Over the sampling period, the hospital effluent had an average flow of $1000 \mathrm{~m}^{3} /$ day and average values of Chemical Oxygen Demand (COD), Biological Oxygen Demand (BOD) and suspended solids of $622 \mathrm{mg} \mathrm{O} / \mathrm{L}, 278 \mathrm{mg} \mathrm{O} / \mathrm{L}$ and $305 \mathrm{mg} / \mathrm{L}$, respectively (source: hospital). The urban wastewater treatment plants, which receives the effluents of this hospital (representing about $0.1 \%$ of the daily flow) is prepared to serve a population equivalent of 200,000 inhabitants, and treats domestic sewage $(>95 \%)$, pre-treated industrial effluents $(<2 \%)$, untreated effluents from different healthcare facilities $(<2 \%)$ and storm water. Over the sampling period, it was registered an average flow of $1.1 \times 10 \mathrm{~m} / \mathrm{day}$, and average values of COD, BOD and suspended solids of $699 \mathrm{mg} \mathrm{O} 2 / \mathrm{L}, 488 \mathrm{mg} \mathrm{O} 2 / \mathrm{L}$ and $334 \mathrm{mg} / \mathrm{L}$ in the raw inflow, and $53 \mathrm{mg} \mathrm{O} 2 / \mathrm{L}, 9 \mathrm{mg} \mathrm{O} 2 / \mathrm{L}$ and $19 \mathrm{mg} / \mathrm{L}$ in the treated effluent, respectively (source: wastewater treatment plant). In the treatment plant, wastewater undergoes a preliminary treatment where fats and bulky solids are 
removed. The sewage water is then decanted in a primary settling tank (primary treatment) and further directed to secondary treatment in a biological reactor responsible for the removal of organic matter, composed of an anoxic (denitrification), an aerated (nitrification) and an endogenous (phosphorous removal) zone. The final treatment consists of sand bed filtration, for the removal of suspended solids. Treated effluent is discharged to a river mouth.

\subsection{Sampling}

Seven samples were collected from the hospital effluent (one per month in October 2010, January-April 2011, June-July 2011), 21 from the raw inflow and 21 from the treated effluent of the wastewater treatment plant (three consecutive days in the months of October 2010eMarch 2011, May 2011) (Fig. S1, S2). Volumes of 5 L of simple samples of hospital effluent or of $24 \mathrm{~h}$ composite samples of raw (after the primary settling tank) and treated wastewater (final effluent) of the waste- water treatment plant were collected in glass sterile bottles and in polypropylene flasks, transported refrigerated to the lab and analyzed within $6 \mathrm{~h}$ for biological analyses, and $24 \mathrm{~h}$ for chemical analyses.

\subsection{Enumeration of cultivable bacteria}

Total and antibiotic resistant bacteria were quantified using the membrane filtration method as described by Novo and Manaia (2010). Briefly, 1-10 mL of decimal serial dilutions were filtered through cellulose nitrate membranes (0.45 $\mathrm{mm}$ pore size, $47 \mathrm{~mm}$ diameter, Advantec MFS, Dublin, CA, USA) and were incubated on plate count agar (PCA, Pronadisa, Madrid, Spain) for total heterotrophs ( $48 \mathrm{~h}$ at $30^{\circ} \mathrm{C}$ ), on $\mathrm{m}$ - faecal coliform (mFC, Difco, Maryland, USA) for enterobacteria ( $48 \mathrm{~h}$ at $30{ }^{\circ} \mathrm{C}$ ), or on glutamate starch phenol-red agar (GSP, Merck, Darmstadt, Germany) which recovers mainly aeromonads/pseudomonads ( $48 \mathrm{~h}$ at $37^{\circ} \mathrm{C}$ ). Since GSP has poor selectivity against Pseudomonas spp. in wastewater samples, incubation was performed at $37^{\circ} \mathrm{C}$, in an attempt to promote the preferential growth of Aeromonas spp., given the good capacity of members of this genus to grow at that temperature (MartinCarnahan and Joseph., 2005). The subpopulations retrieved on the same media supplemented either with $32 \mathrm{mg} / \mathrm{L}$ of amoxicillin (AML, Sigma, Steinheim, Germany) or $4 \mathrm{mg} / \mathrm{L}$ of ciprofloxacin (CIP, Sigma, Steinheim, Germany) were considered resistant to the respective antibiotic. These concentrations of amoxicillin or ciprofloxacin correspond to the minimal inhibitory concentrations and were assayed in previous studies (Novo and Manaia, 2010; CLSI, 2012; Novo 
et al., 2013). All procedures were performed in triplicate. On each culture medium, enumeration was performed for plates displaying 10-90 colony forming units (CFU) (Gerhard et al., 1981). The percentage of antibiotic resistance was deter- mined as the ratio between the CFU/mL formed on the culture medium with and without antibiotic.

\subsection{Bacterial community characterization by DGGE analysis}

Samples filtration, DNA extraction, and 16S rRNA gene based denaturing gradient gel electrophoresis (DGGE) analysis was made as described before (Novo et al., 2013). Briefly, total DNA was extracted in triplicate from 21 samples (seven from the hospital effluent, seven from the raw inflow and seven from the treated effluent, corresponding to the second of the three consecutive days sampled in the wastewater treatment plant), after filtering $150 \mathrm{~mL}$ (wastewater treatment plant treated effluent) or $25 \mathrm{~mL}$ (hospital effluent and wastewater treatment plant raw inflow) through polycarbonate membranes $(0.2 \mathrm{~mm}$ porosity, Whatman, Brentford, UK). DNA extraction was performed using the PowerWater DNA Isolation kit (MOBIO Lab- oratories Inc., Carlsbad, CA, USA), following manufacturer's instructions. The efficiency of DNA extraction was assessed by DNA quantification using fluorometry (QubitTM Fluorometer, Invitrogen, USA). A $180 \mathrm{bp}$ fragment of the 16S rRNA gene, corresponding to the region V3, was amplified using the primers 338F-GC-clamp $\left(5^{0}\right.$ GACTCCTACGGGAGGCAGCAG-30 with a GC clamp) and 518R (50 ATTACCGCGGCTGCTGG-30) (Muyzer et al., 1993). PCR reactions (Biometra), quality control and DGGE analysis (DCode ${ }^{\mathrm{TM}}$ universal mutation detection system, Bio-Rad Laboratories) were made according to previous description (Novo et al., 2013). Approximately $1.8 \mathrm{mg}$ of DNA were loaded on an $8 \%(\mathrm{w} / \mathrm{v})$ vertical polyacrylamide gel with a $28 \%$ e59\% denaturing gradient (where $100 \%$ denaturing gradient is $7 \mathrm{M}$ urea and $40 \%$ deionized formamide. Reproducibility of the DGGE patterns was assessed by including a reference DNA extract with a known DGGE profile in all gels. Gel staining and image visualization and acquisition (Molecular Imager Gel Doc XR system, Bio-Rad Laboratories) were performed as described previously (Barreiros et al., 2008). DGGE profiles were observed visually and further analysed using the Bionumerics software (version 6.1, Applied Maths), with the profiles comprising of reference organisms serving as standard/normalization lanes for inter-gel comparison. Band classes were attributed according to band position and a two- entry table including band intensity value per band class was generated for each DGGE profile, to allow further comparison of samples. 
Bands presenting significant positive correlations with the variation of the concentration of antibiotics, heavy metals or with the percentage of resistant bacteria were selected for identification based on DNA sequencing analysis. In order to detect possible cases of co-migration in a single DGGE band, these bands were excised, amplified, cloned with InsTAaclone ${ }^{\mathrm{TM}}$ cloning kit (Thermo Scientific) and analyzed by DGGE as described by Novo et al. (2013). Clone inserts that matched the original band in the DGGE pattern were sequenced with the primer M13F-pUC (50-GTTTTCCCAGT- CACGAC-30). Nucleotide sequences were checked manually for their quality and their phylogenetic affiliation was deter- mined using the BLAST software (http://blast.ncbi.nlm.nih. gov/) to query the GenBank database.

\subsection{Quantification of micropollutants}

Water samples were characterized for their content of the metals cadmium, chromium, lead, arsenic and mercury and the antimicrobials tetracycline, oxytetracycline, doxycycline, chlorotetracycline, penicillin $G$, penicillin $\mathrm{V}$, sulfamethazine, sulfathiazole, sulfamethoxazole, ciprofloxacin and ofloxacin. Cadmium, chromium and lead content was determined by inductively coupled plasma atomic emission spectroscopy; arsenic content was determined by hydride generation atomic absorption spectroscopy and mercury content was deter- mined by cold vapor atomic absorption spectrometer as described by Novo et al. (2013). Antibiotic content was deter- mined by liquid chromatography coupled with electrospray ionization mass spectrometry, after solid-phase extraction (Novo et al., 2013).

\subsection{Statistical analyses}

Bacterial counts $(\log \mathrm{CFU} / \mathrm{mL})$ and antibiotic resistance percentage values (\%) were compared using one-way ANOVA and the post-hoc Tukey test (SPSS 19.0 for Windows) and considered significantly different when $p<0.01$. Variation of the bacterial communities structure and composition and/or the antibiotic resistance abundance were assessed in function of time, type of water, concentration of antimicrobial residues or percentage of antibiotic resistance using Detrended Correspondence or Canonical Correspondence Analyses (DCA and CCA, software package CANOCO version 4.5). For this purpose two-entry tables of DGGE bands intensity, percentage of antibiotic resistance and concentration of antimicrobial residues were prepared. The significance of the relationship be- tween DGGE patterns, percentage of antibiotic resistance and 
antibiotic/heavy metal residues was tested by Monte Carlo permutations test ( $n$ = 499). Explanatory variables included in CCA analyses were selected by manual forward selection including the permutation test (Monte Carlo permutations test) (Novo et al., 2013).

\section{Results}

\subsection{Quantification of antimicrobial residues}

In general, higher concentrations of ciprofloxacin, ofloxacin, arsenic and mercury were found in the hospital effluent than in the raw inflow (Table 1). In contrast, the concentrations of sulfamethoxazole, tetracycline and penicillin $G$ were lower in the hospital effluent than in the raw inflow. Other antibiotics and metals quantified were, most of the times, below the limit of quantification (LOQ) (Table 1). The concentrations of antibiotics detected varied over time, particularly in the hospital effluent, most probably due to the patterns of utilization and consumption of these antibiotics in the institution (data not available). In the final effluent of the wastewater treatment plant, the concentrations of antibiotics were generally lower than in the raw inflow, although higher inputs corresponded to higher final concentrations. Among the heavy metals examined, in the wastewater treatment plant, mercury was detected above the quantification limit only occasionally and arsenic was always present in concentrations above $2 \mathrm{mg} / \mathrm{L}$. The concentration of arsenic was not reduced after waste- water treatment. The other antibiotics and metals analyzed were found most of the times below the limit of quantification (Table 1).

\subsection{Total and antibiotic resistant cultivable bacterial populations}

The counts of cultivable heterotrophs and aeromonads/ pseudomonads in hospital effluent and in raw inflow were not significantly different $(p>0.01)$, ranging $10^{6} \mathrm{e} 10^{7} \mathrm{CFU} / \mathrm{mL}$. In contrast, the hospital effluent presented significantly lower $(p<0.01)$ counts of enterobacteria than the raw inflow (Fig. S1), differing by one log cycle. Accordingly, hospital effluent presented significantly lower counts of amoxicillin resistant enterobacteria $(p<0.01)$, than the raw inflow. For the other bacterial groups examined, the counts of antibiotic resistant bacteria in hospital effluent and raw inflow were not significantly different and ranged from $10^{5}$ to $10^{7} \mathrm{CFU} / \mathrm{mL}$ (Fig. S1). In the final effluent of the wastewater treatment plant, the counts of total and antibiotic resistant bacteria were about 1.5-2 logarithmic cycles lower for the three bacterial groups. 
The percentage values of amoxicillin and of ciprofloxacin resistant bacteria were compared for the three types of water (Table 2). These two resistance phenotypes revealed different trends. Although higher in hospital effluent than in raw inflow, amoxicillin resistance prevalence did not differ significantly between both sites $(p>0.01)$. In contrast, ciprofloxacin resistance was significantly more prevalent $(p<0.01)$ in the hospital effluent than in the raw inflow, for all the bacterial groups examined. Wastewater treatment did not affect the prevalence of antibiotic resistance, since non-significantly different values were observed between the raw inflow and the treated effluent (Table 2).

\subsection{S rRNA gene-DGGE characterization of the bacterial community}

The characterization of the bacterial community through 16S- rRNA gene based DGGE analysis allowed the assignment of a total of 26 band classes (Table 3, Fig. S2). Among these, seven bands were present in all samples examined from hospital effluent and raw inflow (B1, B5, B6, B7, B9, B19 and B24). These seven bands were detected in all (B5) or in more than half of the treated effluent samples examined, suggesting that the populations represented by these bands may persist from the hospital to the final effluent of wastewater treatment plant (Table 3, Fig. S2). Band intensity, presumably related with population relative abundance, of the DGGE patterns was compared based on a detrended correspondence analysis (DCA). This analysis led to the distribution of the DGGE profiles over two axes, accounting respectively, for $19.4 \%$ and $10.7 \%$ of the bacterial community variation (Figs. S2 and S3). The DCA biplot allowed the distinction of hospital effluent, raw inflow and treated effluent population patterns. Hospital effluent and raw inflow samples separated from treated effluent over axis 1 and hospital effluent samples separated from waste- water treatment plant samples, mainly along axis 2. Although the bacterial communities from the three types of water could be distinguished by DCA analysis, the DGGE patterns of raw inflow were closer to those of hospital effluent than of treated effluent. The bacterial populations of hospital effluent samples collected in April (4) and June (6) differed from those of other hospital effluent samples, being closer to the raw inflow bacterial populations. In opposition, the separation of treated effluent DGGE profiles from all the others, suggests alteration of the wastewater bacterial community during treatment. 
3.4. Correspondence analysis between antimicrobial residues and the cultivable antibiotic resistant bacteria

Canonical correspondence analysis (CCA) evidenced significant correlations between the patterns of variation of the concentration of penicillin $G$, tetracycline, ciprofloxacin and arsenic (Fig. S4A, B) and the percentage of antibiotic resistant bacteria. The variation of the concentration of ciprofloxacin and arsenic was mainly correlated with axis 1, along which were distributed the ciprofloxacin resistant bacterial populations (on PCA, GSP and mFC). Therefore, was evidenced a positive correlation between the variation of the concentration of ciprofloxacin and arsenic and of ciprofloxacin resistance prevalence (Fig. S4A), influenced by hospital effluent samples of March (samples 3 in Fig. S4B). The variation of concentration of penicillin $G$ and tetracycline, distributed over axis 2 , was positively correlated with the variation of the percentage of amoxicillin resistant aeromonads/pseudo- monads. Given the low weight of axis 2, the observed correlation between the variation of penicillin $G$ and tetracycline concentration and percentage of amoxicillin resistance was weaker than that of arsenic and ciprofloxacin concentration with ciprofloxacin resistance.

\subsection{Correspondence analysis between antimicrobial residues and the bacterial community}

CCA evidenced positive significant correlations $(p<0.005)$ between the variation of the concentration of ofloxacin, penicillin G, ciprofloxacin, sulfamethoxazole, tetracycline, arsenic and the intensity of some DGGE bands (Fig. 1A,B). The variation of the concentration of sulfamethoxazole and tetracycline was mainly correlated with axis 1 . The peaks of concentration of these antibiotics in hospital effluent in October and April may explain such a distribution (Fig. 1B, Table 1). Band B7, which comprised bacteria related to the genera Alistipes and Acinetobacter, and band B25 related to the class Clostridia (Table 3, Fig. S2), were those whose variation (in intensity and/or occurrence) presented stronger correlation with the variation of the concentration of those antibiotics. These bands were detected in most hospital effluent and wastewater treatment plant samples. In contrast, the variation of intensity of bands B10, B11, B20 and B21 and of the concentration of sulfamethoxazole and tetracycline was negatively correlated. Most of these bands, although present in hospital effluent and/or raw inflow were more frequent and abundant in treated effluent (Table 3, Fig. S2). Variations in the concentration of fluoroquinolones (ciprofloxacin and ofloxacin) and arsenic were also correlated with changes in the bacterial 
community composition. The variation of the con- centration of fluoroquinolones and arsenic and of populations represented by bands B1, related to the genus Prevotella, B13, related with the genus Faecalibacterium and B24, related with the genus Aeromonas and the class Clostridia, was positively correlated. Bands B1 and B24 were more intense or frequent in hospital effluent and raw inflow than in treated effluent and B13 was present and intense in most of hospital effluent samples (Table 3, Fig. S2). The variation of the intensity of band B26, never detected in the hospital effluent, occasionally observed in the raw inflow and always present in the treated effluent, was negatively correlated with the variation of the concentration of fluoroquinolones and arsenic. In general, the results suggest that within the bacterial community, different populations have variations coincident with fluctuations on the concentration of sulfonamides and tetracyclines or of fluoroquinolones and arsenic.

3.6. Correspondence analysis between cultivable antibiotic resistant bacteria and the bacterial community assessed by DGGE analysis

CCA showed significant correlations between the variation of the percentage of cultivable antibiotic resistant bacteria and DGGE bands intensity (Fig. S5A, $B)$. The variation of the percentage of ciprofloxacin resistant heterotrophs and amoxicillin resistant aeromonads/pseudomonads was mainly distributed over axis 1 . The variation of the percentage of enterobacteria (mFC) resistant to ciprofloxacin and of heterotrophs resistant to amoxicillin was distributed over axes 1 and 2 and of amoxicillin resistant enterobacteria over axis 2 . The sample of hospital effluent of March was probably influencing this pattern of distribution (sample 3 in Fig. S5B). Bands distributed over axis 1 were those which variation in intensity and/or occurrence was most correlated resistance prevalence. Curiously, the DGGE bands whose variation had the strongest correlation with the variation of ciprofloxaxin resistant bacteria and with the variation of the concentration of fluoroquinolones and arsenic were the same, i.e. B1, B13 and B24 (Fig. 1A). In contrast, as observed in the CCA biplot for antimicrobial residues concentrations (Fig. 1A), the variation of band B26, which was never detected in hospital effluent and was always present in treated effluent, was negatively correlated with the variation of the percentage of antibiotic resistant bacteria. 


\section{Discussion}

Because antibiotic consumption is higher and more intense in hospitals than in the community, the development of antibiotic resistant bacteria and the discharge of antimicrobial residues and resistant bacteria in these effluents are supposed to have strong impacts on the spread of antibiotic resistant bacteria in the environment (Kü mmerer and Henninger, 2003; Baquero et al., 2008). The combination of three major adaptation mechanisms may contribute to explain the spread and selection of antibiotic resistant populations: i) the occurrence of horizontal transfer of antibiotic resistance genes (Baquero, 2004; Walsh, 2006); ii) the preferential proliferation of resistant bacteria due to selective pressures imposed by antimicrobial residues or heavy metals (Graham et al., 2011; Tello et al., 2012; Hellweger, 2013) and iii) the bacterial community rearrangement to fit the occurrence of substances with antimicrobial activity, such as antimicrobial residues or heavy metals (Lawrence et al., 2008; Graham et al., 2011; Gillings, 2013; Huerta et al., 2013; Novo et al., 2013). Mechanisms ii) and iii) were those supporting our hypotheses and experimental design. In addition, by comparing wastewater habitats supposedly with different levels of contamination with antimicrobial residues and antibiotic resistant bacteria (hospital and municipal wastewater), we intended to get additional insights about the capability of those contaminants to contribute to shape the bacterial communities. However, it should be noted that the aim of the study was to assess the dynamics of the bacterial populations, and if such variations could be correlated with the occurrence of antimicrobial residues. Since such a dynamics may occur regardless the fact that resistance is acquired or intrinsic, no specific discussion on resistance acquisition by horizontal gene transfer or mutation was addressed in this study.

Though antimicrobial residues and antibiotic resistant bacteria may be more abundant in hospital effluents than in the receiving municipal wastewater treatment plant, the dilution of the hospital effluent in the municipal sewage may blur their possible impacts. The comparison of the concentration of antimicrobial residues or prevalence of antibiotic resistance in both hospital effluent and raw inflow is possible contribute to overcome this artifact. This rationale was used to compare the data regarding antimicrobial residues and heavy metals concentrations and antibiotic resistance prevalence. Among the antimicrobial residues and heavy metals analyzed, only ciprofloxacin and ofloxacin, tetracycline, sulfamethoxazole, penicillin G, and the metals arsenic and mercury were detected regularly at levels above the limit of quantification. Confirming our hypothesis, hospital effluent was observed to be an important 
source of fluoroquinolones and arsenic to the wastewater treatment plant, presenting, in general, higher concentrations than those observed in raw inflow. However, other sources, such as domestic use and other human or veterinary health care facilities, could be responsible for the discharge of sulfamethoxazole, penicillin G and tetracycline to the waste- water treatment plant, since, in general, higher concentrations of these antimicrobials were found in the raw inflow than in the hospital effluent. Regarding antibiotic resistance, hospital effluent presented higher resistance prevalence than the raw inflow or treated effluent for both amoxicillin and ciprofloxacin. However, hospital effluent was not demonstrated as a significant source of amoxicillin resistance. Probably, this was due to the widespread occurrence of intrinsic amoxicillin resistance in environmental bacteria, in particular in Gammaproteobacteria (Paterson, 2006; Parker and Shaw, 2011). In contrast, ciprofloxacin resistance was significantly higher (7e10\%) in hospital effluent than in raw inflow. A positive correlation between ciprofloxacin resistance and the concentration of that antibiotic and arsenic (Fig. S4A) may suggest a selective pressure effect. Indeed, hospital effluent samples collected in March presented the highest concentration of ciprofloxacin, being also those showing the highest percentage of ciprofloxacin resistance. The observation of significant correlations be- tween the concentration of antimicrobial residues and the prevalence of antibiotic resistant bacteria or resistance genes has been reported in previous studies (Huerta et al., 2013; Novo et al., 2013). Huerta et al. (2013) observed an association between macrolides concentration and the normalized number of copies of the genes erm $\mathrm{B}$ and sulI (resistance determinants to macrolides and sulfonamides, respectively), and a negative correlation between $\mathrm{Cd}$ concentration and the abundance of the gene qnrS (resistance determinant to quinolones). Novo et al. (2013) observed a significant positive correlation between tetracyclines concentration and the loads of antibiotic resistant bacteria, although such association was not specifically with tetracycline resistance. As reviewed recently, antibiotic contamination can promote both the mobilization and fixation of resistance genes not only among human and animal commensal bacteria but also between environmental and clinically-relevant species (Baquero et al., 2013; Gillings, 2013). However, major questions are still to be answered. Indeed, the factors that contribute to promote such processes or how these factors interact are not clear yet. The pharmaco-dynamics of the antimicrobial compound as well as the chemical stability or capability to form complexes, and the effect the abiotic conditions such as temperature, $\mathrm{pH}$, or nutrient availability, among others, are probably important elements to clarify the role of these potential selective pressures. 
The environmental contamination with antibiotics has non-target effects at gene, cell, and population levels, since antibiotics can trigger different effects such as SOS response, enhance the mutation rate or promote genetic recombination events (Gillings, 2013). For this reason, as Baquero et al. (2013) emphasized recently, a thorough understanding of antibiotic resistance evolution requires a wide vision of the ecology of bacteria. Rearrangements of the aquatic bacterial communities coinciding with variations on the concentration of antibiotic residues were described for urban and industrial pharmacy wastewater or for surface water (Li et al., 2011; Huerta et al., 2013; Novo et al., 2013). As Novo et al. (2013) reported before, also in this study sulfamethoxazole and tetracycline presented a pattern of correlation with the bacterial community distinct of that observed for quinolones. Although the simultaneous measurement of the concentration of antimicrobial agents and of biological indicators (bacterial populations or genes) seems to be an interesting approach to assess possible effects of the pollutants on the microbiota (Graham et al., 2011; Huerta et al., 2013; Novo et al., 2013), it is important to bear in mind the numerous bias that may be involved. In particular, the mobility and half-life of different antimicrobial agents, which are also influenced by the environment where they are discharged, are expected to have a strong influence. For instance, cipro- floxacin is recognized by its high sorption capacity, while tetracyclines, also with high sorption potential, are able to form complexes with calcium or magnesium (Kü mmerer, 2009). On the other hand, penicillin $G$ is expected to be rapidly hydrolyzed in the environment due to microbial activity, while sulfonamides, despite the expected elimination by sorption are common contaminants of aquatic environments (Halling-Sørensen et al., 1998; Kümmerer, 2009). Nevertheless, in this study it was suggested that the bacterial populations of the hospital effluent, more than those from raw inflow, can respond to variations of antibiotic concentrations, even when higher concentrations are found in raw inflow. This was observed for tetracyclines and sulfonamides (Fig. 1B). It is thus suggested that hospital effluents can be interesting models to study relationships between antimicrobial residues and bacterial populations.

The observation of significant positive correlations between the variation of the concentration of antimicrobial residues and the presence of some members of the bacterial community may suggest that some of those micropollutants may have a role in shaping the bacterial communities. Variations on the abundance of members of the classes Gam- maproteobacteria, Bacteroidia and Clostridia, represented by bands B1, B13 and B24, were correlated with the variation of the concentration of antimicrobial residues. For some of those bacterial groups, not 
much is known in terms of anti- biotic resistance. Nevertheless, it is interesting to note that the same bacterial populations, represented by bands B1, B13 and B24, were also positively correlated with the variation of the percentage of cultivable antibiotic resistant bacteria. These results are in line with the study of Novo et al. (2013), suggesting that some environmental bacteria may be influenced by the occurrence of antimicrobial residues and anti- biotic resistant bacteria. In that study, the occurrence of Epsilonproteobacteria (related with the genera Arcobacter and Sulfurimonas) was positively correlated with the concentra- tion of antibiotics. Studies seeking for possible relationships between bacterial community variations and the contamination with antimicrobial residues (Huerta et al., 2013; Novo et al., 2013; the present study) may contribute to assess the potential of antimicrobial agents in disturbing the bacterial communities or in exerting selective pressure effects. As hypothesized in our experimental design, the comparison and multivariate analyses of habitats with different levels of antimicrobial residues and antibiotic resistant bacteria may bring interesting insights into the relationship between antibiotic resistance, antibiotic residues and bacterial populations in water. Hospital effluent was confirmed as an important, although not unique, source of, antimicrobial residues and antibiotic resistant bacteria in wastewater treatment plant. Since there are recognized limitations for the complete removal of antibiotic resistant bacteria and/or antibiotic residues in conventional wastewater treatment systems (Galvin et al., 2010; Czekalski et al., 2012; Chen and Zhang, 2013; Novo et al., 2013), special attention should be given to the discharge of untreated hospital effluents into the municipal collectors.

\section{Conclusions}

- Ciprofloxacin resistance was significantly more prevalent $(p<0.01)$ in hospital effluent than in raw inflow, for all the bacterial groups studied. In contrast, amoxicillin resistance prevalence was not significantly different in both sites $(p>0.01)$.

- Ciprofloxacin and arsenic concentrations were positively correlated with ciprofloxacin resistance prevalence, mainly in hospital effluent samples.

- The bacterial populations correlated with the concentrations of sulfamethoxazole and tetracycline were different of those correlated with ciprofloxacin, ofloxacin and arsenic;

- A positive correlation was observed between the concentration of sulfamethoxazole and tetracycline and the intensity of the DGGE bands 
comprising of members of the classes Bacteroidia and Gammaproteobacteria.

A positive correlation was observed between the concentrations of ciprofloxacin, ofloxacin and arsenic and the intensity of the DGGE bands comprising of members of the classes Clostridia, Gammaproteobacteria and Bacteroidia.

- Higher intensities of DGGE bands comprising of the bacterial groups Bacteroidia and Clostridia were found in samples presenting both higher concentration of fluoroquinolones and arsenic and ciprofloxacin resistant bacteria.

\section{Acknowledgments}

This work was supported by National Funds from FCT e Fundação para a Ciência e a Tecnologia through projects PEst- OE/EQB/LA0016/2011 and PTDC/AACAMB/113840/2009 and ARV grant SFRH/BD/70986/2010. Authors gratefully acknowledge the engineers at the hospital facilities and wastewater treatment plant for their support.

\section{Appendix A. Supplementary data}

Supplementary data related to this article can be found at http://dx.doi.org/10.1016/j.watres.2014.02.003.

\section{References}

Andersson, D.I., Hughes, D., 2010. Antibiotic resistance and its cost: is it possible to reverse resistance? Nat. Rev. Microbiol. 8, 260-271.

Andersson, D.I., Hughes, D., 2012. Evolution of antibiotic resistance at nonlethal drug concentrations. Drug. Resist. Updat. 15, 162-172.

Baquero, F., 2004. From pieces to patterns: evolutionary engineering in bacterial pathogens. Nat. Rev. Microbiol. 2, 510-518.

Baquero, F., Martínez, J.-L., Cantó n, R., 2008. Antibiotics and antibiotic resistance in water environments. Curr. Opin. Biotechnol. 19, 260-265.

Baquero, F., Tedim, A.P., Coque, T.M., 2013. Antibiotic resistance shaping multi-level population biology of bacteria. Front.Microbiol. 4, 1-15.

Barreiros, L., Fernandes, A., Ferreira, A.C.S., Pereira, H.,Bastos, M.M.S.M., Manaia, C.M., Nunes, O.C., 2008. New insights into a bacterial metabolic and detoxifying association responsible for the mineralization of the thiocarbamate herbicide molinate. Microbiology 154, 1038-1046. 
Chen, H., Zhang, M., 2013. Effects of advanced treatment systems on the removal of antibiotic resistance genes in wastewater treatment plants from Hangzhou, China. Environ. Sci.Technol. 47 (15), 8153-8157.

CLSI, 2012. Performance Standards for Antimicrobial Susceptibility Testing; Twenty-first Informational Supplement. CLSI document M100-S21. Clinical and Laboratory Standards Institute, Wayne, PA, USA.

Czekalski, N., Berthold, T., Caucci, S., Egli, A., Bü rgmann, H., 2012. Increased levels of multiresistant bacteria and resistance genes after wastewater treatment and their dissemination into Lake Geneva, Switzerland. Front. Microbiol. 3, 118.

Davies, J., Davies, D., 2010. Origins and evolution of antibiotic resistance origins and evolution of antibiotic resistance. Microbiol. Mol. Biol. Rev. 74 (3), 417-433.

French, G.L., 2010. The continuing crisis in antibiotic resistance. Int. J. Antimicrob. Agents 36, S3-S7.

Galvin, S., Boyle, F., Hickey, P., Vellinga, A., Morris, D., Cormican, M., 2010. Enumeration and characterization of antimicrobial-resistant Escherichia coli bacteria in effluent from municipal, hospital, and secondary treatment facility sources. Appl. Environ. Microbiol. 76 (14), 4772-4779.

Gerhard, P., Murray, R., Costilo, W., Nester, E., Wood, W., Krieg, N., 1981. Manual of Methods for General Bacteriology. American Society of Microbiology, Washington, DC.

Gillings, M.R., 2013. Evolutionary consequences of antibiotic use for the resistome, mobilome and microbial pangenome. Front. Microbiol. 4, 1-9.

Graham, D.W., Olivares-Rieumont, S., Knapp, C.W., Lima, L., Werner, D., Bowen, E., 2011. Antibiotic resistance gene abundances associated with waste discharges to the Almendares River near Havana, Cuba. Environ. Sci. Technol. $45,418-424$.

Halling-Sørensen, B., Nors Nielsen, S., Lanzky, P.F., Ingerslev, F., Holten Lü tzhøft, H.C., Jørgensen, S.E., 1998. Occurrence, fate and effects of pharmaceutical substances in the environment e a review. Chemosphere 36 (2), 357-393.

Harris, S., Morris, C., Morris, D., Cormican, M., Cummins, E., 2013. The effect of hospital effluent on antimicrobial resistant E. coli within a municipal wastewater system. Environ. Sci. Process. Impacts 15, 617-622.

Hellweger, F.L., 2013. Escherichia coli adapts to tetracycline resistance plasmid (pBR322) by mutating endogenous potassium transport: in silico hypothesis testing. FEMS Microbiol. Ecol. 83, 622-631.

Huerta, B., Marti, E., Gros, M., Ló pez, P., Pompêo, M., Armengol, J., Barceló , D., Balcá zar, J.L., Rodríguez-Mozaz, S., Marcé, R., 2013. Exploring the links between 
antibiotic occurrence, antibiotic resistance, and bacterial communities in water supply reservoirs. Sci. Total Environ. 456e457, 161-170.

Jakobsen, L., Sandvang, D., Hansen, L.H., Bagger-Skjøt, L., Westh, H., Jørgensen, C., Hansen, D.S., Pedersen, B.M., Monnet, D.L., Frimodt-Møller, N., Sørensen, S.J., Hammerum, A.M., 2008. Characterisation, dissemination and persistence of gentamicin resistant Escherichia coli from a Danish university hospital to the waste water environment. Environ. Int. 34, 108-115.

Kim, S., Aga, D.S., 2007. Potential ecological and human health impacts of antibiotics and antibiotic-resistant bacteria from wastewater treatment plants. J. Toxicol. Environ. Health, Part B 10, 559-573.

Kü mmerer, K., 2009. Antibiotics in the aquatic environment $e$ a review e part I. Chemosphere 75 (4), 417-434.

Kü mmerer, K., Henninger, A., 2003. Promoting resistance by the emission of antibiotics from hospitals and households into effluent. Clin. Microbiol. Infect. Dis. 9 (12), 1203-1214.

Lawrence, J.R., Zhu, B., Swerhone, G.D.W., Topp, E., Roy, J., Wassenaar, L.I., Rema, T., Korber, D.R., 2008. Community-level assessment of the effects of the broad-spectrum antimicrobial chlorhexidine on the outcome of river microbial biofilm development. Appl. Environ. Microbiol. 74 (11), 3541-3550.

Li, D., Qi, R., Yang, M., Zhang, Y., Yu, T., 2011. Bacterial community characteristics under long-term antibiotic selection pressures. Water Res. 45, 6063-6073.

Manaia, M., Vaz-Moreira, I., Nunes, O.C., 2012. Antibiotic resistance in waste water and surface water and human health implications. In: The Handbook of Environmental Chemistry: Emerging Organic Contaminants and Human Health.

Martin-Carnahan, A., Joseph, S.W., 2005. Genus I. Aeromonas Stanier 1943, 213AL. In: Brenner, D.J., Krieg, N.R., T Staley, James, Garrity, G.M. (Eds.), Bergey's Manual of Systematic Bacteriology. Springer, New York.

Martinez, J.L., 2009. Environmental pollution by antibiotics and by antibiotic resistance determinants. Environ. Pollut. 157, 2893-2902.

Michael, I., Rizzo, L., McArdell, C.S., Manaia, C.M., Merlin, C., Schwartz, T., Dagot, C., Fatta-Kassinos, D., 2013. Urban wastewater treatment plants as hotspots for the release of antibiotics in the environment: a review. Water Res. 47 (3), 957-995.

Muyzer, G., Waal, E.C., de Uitierlinden, A.G., 1993. Profiling of complex microbial populations by denaturing gradient gel electrophoresis analysis of polymerase chain Reaction- Amplified Genes coding for 16S rRNA. Appl. Environ. 
Microbiol. 59 (3), 695-700.

Novo, A., André, S., Viana, P., Nunes, O.C., Manaia, C.M., 2013. Antibiotic resistance, antimicrobial residues and bacterial community composition in urban wastewater. Water Res. 47 (5), 1875-1887.

Novo, A., Manaia, C.M., 2010. Factors influencing antibiotic resistance burden in municipal wastewater treatment plants. Appl. Microbiol. Biotechnol. 87 (3), 1157-1166.

Oberlé, K., Capdeville, M., Berthe, T., Budzinski, H., Petit, F., 2012. Evidence for a complex relationship between antibiotics and antibiotic-resistant Escherichia coli: from medical center patients to a receiving environment. Environ. Sci. Technol. 46, 1859-1868.

Parker, J.L., Shaw, J.G., 2011. Aeromonas spp. clinical microbiology and disease. J. Infect. 62 (2), 109-118.

Paterson, D.L., 2006. Resistance in Gram-negative bacteria: Enterobacteriaceae. Am. J. Med. 119 (6), S20-S28.

Rizzo, L., Manaia, C., Merlin, C., Schwartz, T., Dagot, C., Ploy, M.C., Michael, I., Fatta-Kassinos, D., 2013. Urban wastewater treatment plants as hotspots for antibiotic resistant bacteria and genes spread into the environment: a review. Sci. Total Environ. 447, 345-360.

Tello, A., Austin, B., Telfer, T.C., 2012. Selective pressure of antibiotic pollution on bacteria of importance to public health. Environ. Health Perspect. 120 (8), 1100-1106.

Varela, A.R., Manaia, C.M., 2013. Human health implications of clinically relevant bacteria in wastewater habitats. Environ. Sci. Pollut. Res. 20, 3550-3569.

Walsh, T.R., 2006. Combinatorial genetic evolution of multiresistance. Curr. Opin. Microbiol. 9, 476-482. 

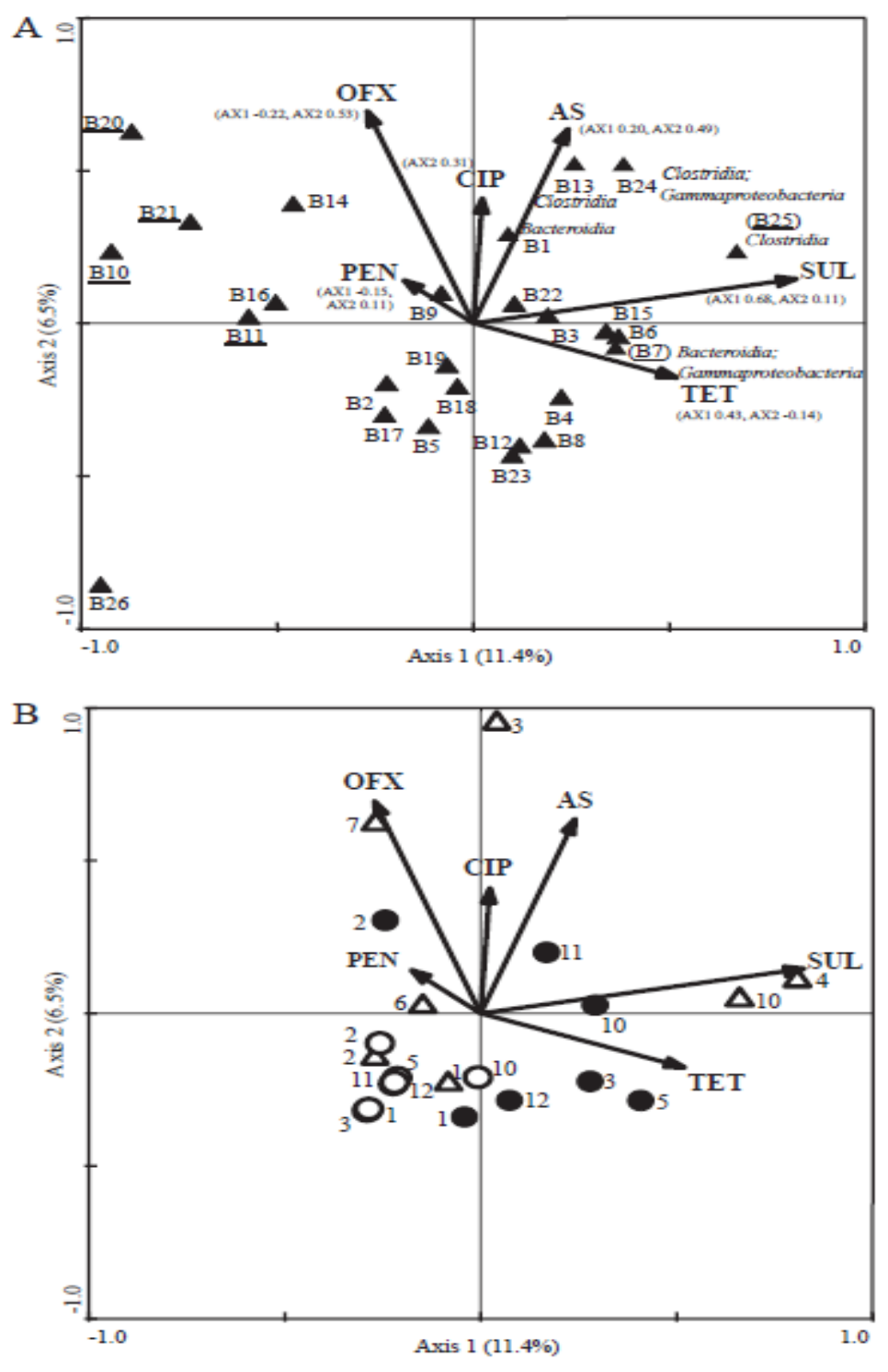

Fig. 1 - Figure 1A. Correspondence Canonical Analysis (CCA) of the variation of 16S rRNA gene-DGGE patterns of hospital effluent, urban wastewater treatment plant raw inflow and treated effluent (the score of variation of the DGGE bands, :, was of 0.615, $11.4 \%$ over axis 1 and $6.5 \%$ over axis 2 ), in function of the concentration of antimicrobial residues tetracycline (TET, $\mathrm{p}=0.002)$, sulfamethoxazole $(\mathrm{SUL}, \mathrm{p}=0.002)$, ciprofloxacin (CIP, $p=0.002)$, penicillin $\mathrm{G}(\mathrm{PEN}, \mathrm{p}=0.018)$, ofloxacin (OFX, $\mathrm{p}=0.002)$ and arsenic (AS, $p=0.002)$. Only the variables significantly $(p<0.05)$ explaining the observed community variation are shown. The specieseenvironmental correlations for axes 1 and 2 were, respectively, 0.829 and 0.765 . $16 \mathrm{~S}$ rRNA gene-DGGE bands with a fraction of variance over axes 1 higher than 0.2/1 are underlined. Figure 1B. Correspondence Canonical Analysis (CCA), as described in Fig. 1A. Samples of hospital effluent (6) and of the raw inflow (C) or treated effluent (B)of wastewater treatment are numbered according to the month of collection (1, Januarye12, December). Sampling occurred between October 2010 and July 2011. 
Table 1 - Concentration of antibiotic residues and heavy metals determined in wastewater over the sampling period.

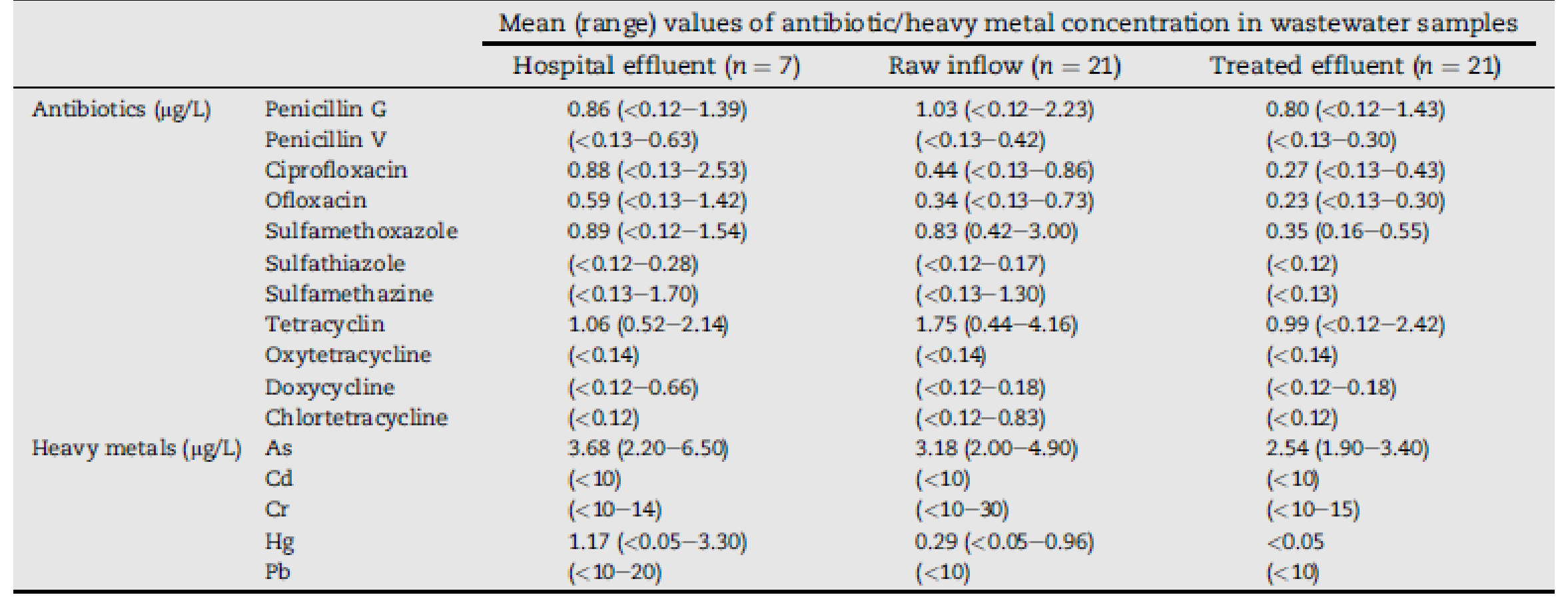




\section{Table 2 - Prevalence of antibiotic resistance prevalence in wastewater over the sampling period.}

\begin{tabular}{llcr} 
Bacterial group (Isolated on) & Wastewater samples & Mean (range) values of antibiotic resistance prevalence (\%) \\
\cline { 3 - 4 } & & $+32 \mu \mathrm{g} / \mathrm{mL}$ amoxicillin & $+4 \mu \mathrm{g} / \mathrm{mL}$ ciprofloxacin \\
\hline Heterotrophs (PCA) & Hospital effluent $(n=7)$ & $37.8 \mathrm{a}(11.2-77.6)$ & $19.5 \mathrm{a}(1.6-40.3)$ \\
& Raw inflow $\left(n=20^{\circ}\right)$ & $28.3 \mathrm{a}, \mathrm{b}(9.5-68.0)$ & $7.6 \mathrm{~b}(0.6-37.5)$ \\
& Treated effluent $\left(n=20^{\mathrm{a}}\right)$ & $23.7 \mathrm{~b}(1.6-66.3)$ & $9.3 \mathrm{~b}(0.4-80.1)$ \\
Aeromonads/Pseudomonads (GSP) & Hospital effluent $(n=7)$ & $48.8 \mathrm{a}(10.3-82.5)$ & $10.7 \mathrm{a}(1.2-35.2)$ \\
& Raw inflow $\left(n=20^{-7}\right)$ & $41.3 \mathrm{a}, \mathrm{b}(1.5-94.6)$ & $3.7 \mathrm{~b}(0.1-17.6)$ \\
& Treated effluent $\left(n=20^{\mathrm{a}}\right)$ & $29.0 \mathrm{~b}(5.4-72.1)$ & $3.3 \mathrm{~b}(0.2-31.6)$ \\
Enterobacteria (mFC) & Hospital effluent $(n=7)$ & $52.7 \mathrm{a}(4.0-91.9)$ & $15.8 \mathrm{a}(0.6-52.5)$ \\
& Raw inflow $\left(n=20^{\circ}\right)$ & $45.7 \mathrm{a}(0.2-88.5)$ & $3.5 \mathrm{~b}(0.1-14.1)$ \\
& Treated effluent $\left(n=20^{\mathrm{a}}\right)$ & $46.4 \mathrm{a}(0.1-96.9)$ & $5.1 \mathrm{~b}(<0.1-18.9)$
\end{tabular}

$a, b-$ significantly different $(p<0.01)$ in the three types of water on the basis of post hoc Tukey test for the comparison of samples of different origins.

a No data was available for one sample. 
Table 3 - Presence, dominance and affiliation of bacterial populations, represented by DCGE bands, which were positively correlated with the concentration of antibiotic residues and heavy metals or the prevalence of antibiotic resistance.

\begin{tabular}{|c|c|c|c|c|c|}
\hline \multirow[t]{3}{*}{ Band } & \multirow[t]{3}{*}{ Affiliation } & \multicolumn{3}{|c|}{$\begin{array}{c}\text { Presence (number of occurrences/ } \\
\text { number of samples; \%) }\end{array}$} & \multirow[t]{3}{*}{$\begin{array}{l}\text { Correlated with: concentration/ } \\
\text { resistance percentage }\end{array}$} \\
\hline & & \multicolumn{3}{|c|}{$\begin{array}{l}\text { Dominance (number of occurrences } \\
\text { with more than } 1 / 2 \text { of the maximum intensity } \\
\text { detected/number of samples; } \% \text { ) }\end{array}$} & \\
\hline & & $\begin{array}{l}\text { Hospital } \\
\text { effluent }\end{array}$ & $\begin{array}{l}\text { Raw } \\
\text { inflow }\end{array}$ & $\begin{array}{l}\text { Treated } \\
\text { effluent }\end{array}$ & \\
\hline B1 & $\begin{array}{l}\text { Bacteroidetes, related with } \\
\text { the genus Prevotella } \\
\text { (AB649279.1, 99\%; AB244770.1, 98\%) }\end{array}$ & $\begin{array}{r}100 \\
57\end{array}$ & $\begin{array}{r}100 \\
14\end{array}$ & $\begin{array}{l}57 \\
14\end{array}$ & $\begin{array}{l}\text { Ciprofloxacin, ofloxacin, } \\
\text { arsenic/ciprofloxacin resistance }\end{array}$ \\
\hline B7 & $\begin{array}{l}\text { Bacteroidetes, related with } \\
\text { the genus Alistipes } \\
\text { (AB554232.1, 100\%) } \\
\text { Proteobacteria, related with the } \\
\text { genus Acinetobacter } \\
\text { (KF049130.1, 99\%) }\end{array}$ & $\begin{array}{r}100 \\
71\end{array}$ & $\begin{array}{l}100 \\
100\end{array}$ & $\begin{array}{l}71 \\
29\end{array}$ & Sulfamethoxazole, tetracycline \\
\hline B13 & $\begin{array}{l}\text { Firmicutes, related with the } \\
\text { genus Faecalibacterium } \\
\text { (JN037416.1, 100\%) }\end{array}$ & $\begin{array}{r}100 \\
86\end{array}$ & $\begin{array}{r}57 \\
0\end{array}$ & $\begin{array}{r}57 \\
0\end{array}$ & $\begin{array}{l}\text { Ciprofloxacin, ofloxacin, } \\
\text { arsenic/ciprofloxacin resistance }\end{array}$ \\
\hline B24 & $\begin{array}{l}\text { Proteobacteria, related with } \\
\text { the genus Aeromonas } \\
\text { (KC906261.1, 100\%) } \\
\text { Firmicutes, related with the } \\
\text { class Clostridia (JN713307.1, 94\%) }\end{array}$ & $\begin{array}{r}100 \\
71\end{array}$ & $\begin{array}{r}100 \\
43\end{array}$ & $\begin{array}{r}86 \\
0\end{array}$ & $\begin{array}{l}\text { Ciprofloxacin, ofloxacin, } \\
\text { arsenic/ciprofloxacin resistance }\end{array}$ \\
\hline B25 & $\begin{array}{l}\text { Fimicutes, related with the } \\
\text { class Clostridia (NR_102880.1, 100\%) }\end{array}$ & $\begin{array}{l}86 \\
14\end{array}$ & $\begin{array}{r}100 \\
43\end{array}$ & $\begin{array}{r}86 \\
0\end{array}$ & Sulfamethoxazole, tetracycline \\
\hline
\end{tabular}

